\title{
A VONTADE ENTRE A GRÉCIA CLÁSSICA E O CRISTIANISMO
}

André Rangel Rios*

SINTESE - O texto comenta a discussão de Ch. H. Kahn sobre a vontade na Antigüidade Tardia. O comentário a Kahn é base para colocar em questão a relação entre o pensamento grego e a tradição judaico-cristã. É discutida em particular a função da doutrina da graça e sua complexa relação com a herança greco-romana.
ABSTRACT - The text comments the discussion of Ch. H. Kahn about the will in the Late Antiquity. The commentary is the ground to put the question about the relationship between Greek Philosophy and the Jew-Christian tradition. The text discusses particulary the function of the divine grace and its complex relationship with the Greek-Roman heritage.

Após discutir quais são as diferenças entre o conceito de vontade de Agostinho e o dos gregos Charles Kahn em seu artigo "Discovering the will. From Aristotle to Augustine ${ }^{11}$ resume sua posição em três pontos:

1. O conflito psíquico que Platão apreendia ao distinguir a alma em três partes (razão, thumós e apetite) é descrito em Agostinho como a fragmentação de um só princípio, a saber, da voluntas. $\mathrm{O}$ eu cindido é a vontade cindida.

2. O sentido da alienação do próprio eu, a frustração de não poder realizar o que se supõe desejar mais intimamente, é expresso em termos de uma ordem da própria vontade que a própria vontade não obedece. Há que se notar que enquanto para Platão é a razão (lógos, to logístikon) quem dá as ordens, em Agostinho é a voluntas que o faz.

3. A vontade não pode se apreender totalmente, o eu não pode se unificar por si só. Só é possivel se alcançar a paz espiritual com o auxilio do Criador (inquietum est cor nostrum donec in te requiescat). ${ }^{2}$

Ou seja, o conceito de vontade, que não existira nos gregos, seria o conceito de uma vontade exercida por uma instância espiritual única que, porém, seria cindida nela mesma, incapaz de prestar contas aprofundadamente de si mesma para

- Universidade Estadual do Rio de Janeiro - UERJ.

1 Charles H. Kahn "Discovering the will: From Aristotle to Augustine" in: The question of "Eclectism". Studies in Later Greek Philosophy. Berkeley, University of California Press, 1988 p. 234-259:

2 Ib. p. 257-258. 
si mesma, embora seja esta instância que constituiria mais essencialmente o verdadeiro eu (ao contrário de Platão e Aristóteles que teriam antes o nous como o "true self"). ${ }^{3}$

Kahn pretende assim estar concordando com a tese de Dihle $e^{4}$ que considera que é a tradição judaico-cristã que determina este conceito de vontade, pois é nela que se vê a vontade humana (enquanto uma instância distinta da razão e do apetite natural) emergindo - ao superar tudo o mais - como uma atitude de obediência ou desobediência à vontade de Deus. Tal concepção da vontade teria sido articulada assim somente em Agostinho, embora só tenha vindo a ser integrada numa teoria geral da vontade por Tomás de Aquino. Kahn pretende estar apenas nuanceando melhor a tese de Dihle ao enfatizar - sem contestar que a tradição judaico-cristã seja aqui a principal - transformações conceituais na tradição grega relevantes para a elaboração agostiniana do conceito de vontade. Ele lembra que os grandes desenvolvimentos históricos são sempre superdeterminados. ${ }^{5}$ Sendo assim, Kahn indica várias transformações na própria tradição greco-latina que também teriam preparado a concepção agostiniana de vontade. Estas transformações seriam principalmente três: (1) A focalização do elemento volitivo na teoria estóica do assentimento. (2) A aproximação entre boúleusis e hekoúsios devida à tradução latina por Cícero respectivamente por voluntas e voluntarium. (3) A concepção de Epicuro da proaíresis, de nossa capacidade de escolha, como a possibilidade de gerir o que "depende de nós" (ep'hemin), ou seja, contrariamente ao que não depende de nós como o corpo, a reputação, as propriedades, a posição politica etc., que são assuntos sob os quais não temos como influir, podemos gerir nossos julgamentos, nossos impulsos, nosso desejo racional, nossas aversões etc. O conceito de voluntas em Sêneca seria, segundo Kahn, semelhante ao de proairesis em Epicuro. Este desvio do conceito de proairesis ou voluntas seria extremamente importante na evolução do conceito de pessoa e de eu. ${ }^{6}$ Seria toda uma preocupação com a vida interior que teria se acentuado então. A terminologia grega tradicional não teria nenhum termo apropriado para esta intensa preocupação com a vida interior.

$O$ determinante na mudança do conceito de vontade teria sido a vivência bíbli$\mathrm{ca}^{7}$ a qual teria proporcionado a concepção de um dilaceramento da vontade e da preponderância desta vontade dilacerada sobre as outras faculdades, como razão e apetite natural. Mas é este pensamento de uma vontade cindida exclusiva da tradição judaico-cristã? $\mathrm{O}$ que é afinal uma tradição? E como duas tradições podem se unir? Há, como propõe Heidegger, uma separação intransponível entre estas duas tradições? São, sem dúvida, questões importantes, mas a prudência não nos deixará avançar além de uma breve discussão da primeira delas.

3 Ib. p. 235.

4 Albrecht Dihle The Theory of Will in Classical Antiquity. Berkeley and Los Angeles, 1982 (a referência é de Kahn p. 236 nota 1).

5 Kahn p. 259: "Major historical developments are always overdeterminated."

6 Ib. p. 253: "This shift is a momentous one for the evolution of the idea of person and selfhood."

7 Ib. p. 255: "From St. Paul and his own experience of conversion he [Agostinho] derived the sense of the divided self". Kahn destaca Paulo Aos Romanos: "não faço o bem que quero [thelo], mas pratico o mal que não quero [ou thelo]". 
Um determinismo rigoroso (fisico e psicológico) é uma economia restrita: tudo tem seu preço (isto é, tudo tem uma causa) e tudo pode ser revertido (causar) uma vez pago um preço equivalente (conseqüências). Assim, temos um sistema fechado, sem perdas ou ganhos, que se auto-reproduz. Aristóteles não defende um determinismo estrito. Para ele há na natureza a contingência. É no espaço desta contingência físico-biológica que o homem pode exercer sua capacidade de deliberação e escolha. A rigor o homem para Aristóteles se encontra entre dois acasos: 0 da natureza e o do seu próprio nascimento na sociedade. $O$ homem então vê-se entregue às suas próprias forças, abandonado por um Deus sobremodo distante. 0 Deus de Aristóteles é o ideal de uma economia restrita e auto-suficiente, uma economia que o homem (e só alguns) consegue estabelecer individualmente e que só raramente é também obtido por uma polis. A tendência é que os homens não consigam alcançar a auto-suficiência e assim suprir a Providência precária do mundo sublunar.

Em Aristóteles o dilaceramento está primeiramente na natureza, a natureza é incapaz de estabelecer uma economia restrita, suas cadeias causais, devido à influência da matéria, se rompem e a tendência ao caos nunca recua; com a boúleusis, a proaíresis e a frónesis o homem tenta reverter esta tendência ao caos e estabeler uma ordem, isto é, uma economia restrita, ao menos no campo da Ética (e da Política). Porém, são poucos que o conseguem, em grande parte os homens não chegam a atingir a eudaimonía cedendo terreno ao caos; contudo há muitos que conseguem se manter em um meio caminho, o que já possibilita que a pólis se organize e que os poucos mais persistentes e mais favorecidos pelo acaso alcancem a eudaimonía. De certa maneira, pode-se dizer que é na natureza que está primeiramente a tendência ao caos e só secundariamente no homem, contudo tal tendência está também no homem e o homem só é compreendido como homem enquanto ele é tido como passível de fracasso, isto é, de vícios - e de virtude. Nem os animais nem os deuses deliberam ou escolhem, é portanto próprio ao homem tanto escolher bem quanto mal. Sendo assim está na natureza humana abandonar o caminho que lhe seria o mais apropriado. Há assim uma cisão na vontade do homem, embora ela não seja exaltada ou cultivada. $O$ que difere uma tradição da outra não é que uma tenha o conceito de uma vontade dilacerada e a outra não, o que difere é que uma tem um discurso sobre o dilaceramento da vontade e a outra não. 0 conceito de uma estrutura ontológica de uma vontade dilacerada vem antes basicamente dos gregos, dos cristãos provém 0 discurso sobre $o$ dilaceramento insuperável da vontade sem o auxilio de Deus. Se em Aristóteles alcançar a auto-suficiência era reservado para poucos, com a exacerbação do dilaceramento do discurso sobre o descontrole da vontade por ela mesma alcançar a auto-suficiência, a pacificação torna-se impossível para o homem sem ser auxiliado por Deus.

Sendo assim, pode-se dizer que o conceito de vontade em Agostinho muda nem tanto porque ele concentra em uma só instância as tensões que se dividiam, p. ex., em Platão, entre as várias partes da alma, mas o que muda é ele aceitar como certo que é impossivel para o homem ter certeza de que sua vontade não quererá o mal. Para os gregos era possivel, ainda que difícil e reservado para pou- 
cos, que o homem se educasse para ser justo e feliz. Em Agostinho é possivel que um homem se eduque para ser justo e feliz, nunca se poderá porém estar certo (nem o próprio homem que se esforça por ser virtuoso) que as virtudes de um homem não sejam senão hipocrisia. E o discurso de que o homem sempre pode estar agindo contrariamente ao que ele próprio supõe sinceramente querer chega a Agostinho através de Paulo. Ontologicamente não me parece essencial se esta cisão se localiza em uma só instância ou se se divide em várias (não deveria até ser maior o dilaceramento?).

O que está em questão é antes como é possivel se estabelecer uma economia dos atos volitivos. Tanto antes de Agostinho quanto depois de Agostinho há a idéia de que é possivel se estabelecer uma economia dos atos volitivos e também que tal economia é largamente sujeita ao fracasso, isțo é, a não alcançar a auto-suficiência. Em Agostinho há a ênfase de que uma economia dos atos de vontade necessita sempre de 'ser suplementada por graças divinas. Durante séculos os teólogos discutirão quais graças são necessárias e como se pode evitar uma inflação desenfreada de graças. Nunca se chegará (e desde Agostinho já se tinha isto como impossivel e mesmo herético) a estabelecer uma economia restrita contabilizando só os atos de vontade sem o auxílio de graças divinas. Já o estabelecimento de uma economia restrita contabilizando tanto os atos de vontade quanto. as graças divinas seguiu em debate. A polêmica em torno da scientia media é uma polêmica em torno do estabelecimento de uma economia restrita dos atos da vontade. O fracasso desta polêmica confirma, o que de certo modo sempre se supôs, a impossibilidade também desta economia.

Porém a possibilidade do fracasso no estabelecimento desta economia remete, como já vimos, aos gregos. Para Aristóteles é possivel que uns poucos alcancem a eudaimonía, logo é possivel o fracasso, logo há sempre o fracasso, pois qualquer um que vivesse um pouco mais poderia ver rompido o seu equilíbrio eudaimônico por alguma contingência, ou seja, pela morte dos filhos, pela miséria ou pela doença. Sendo assim, de certo modo, seja qual seja o sucesso, ele é sempre essencialmente assombrado pela possibilidade do fracasso e é, portanto, já um fracasso. Deste modo, no cristianismo, buscar estabelecer uma economia restrita dos atos da vontade é prosseguir o projeto filosófico grego. O projeto grego é mantido mas é criticado como insuficiente, pois fica evidenciado que algo a mais é necessário, a saber, o auxilio da graça para que o homem se volte para Deus e que persista seguindo a Deus. É só porque o homem por sua própria vontade se volta para Deus que ele pode ser salvo, mas o homem por si só não pode nem voltar-se para Deus nem persistir na obediência a Deus; só com o auxọlio da graça o homem pode voltar-se para Deus e assim perseverar, mas a graça não suprimiria a liberdade da vontade, apenas a suplementaria. Assim se poderia estabelecer uma economia restrita de toda a história humana. No princípio alguns homens seriam escolhidos por Deus para serem salvos. Deus então criaria um mundo e o sustentaria existindo (logo a questão de uma contingência natural fica sem importância; a contingência no mundo fica reduzida às vicissitudes da vontade sempre inconstante dos homens) e cria neste mundo a humanidade com os seus predestinados. Toda a dificuldade está em como Deus pode seguir onisciente e onipotente sem suprimir a li- 
berdade dos homens, pois Deus só salvará os que nele crerem e a ele amarem. A graça deverá fazer com que os escolhidos não só se voltẹm para Deus mas que o façam por sua própria vontade, com uso de sua liberdade. O mistério da graça está em como ela influi na vontade sem suprimir a liberdade. A graça deverá funcionar como uma moeda falsa, deverá "enriquecer" a vontade do predestinado de modo que ele possa mais facilmente "comprar" aquilo com o que ele antes não pretendia "gastar", mas sem que ele venha com este "enriquecimento" a ser "corrompido", isto é, sem que ele deixe de ser ele mesmo. Os teólogos sempre tentaram explicar o funcionamento do suplemento da graça, sempre tentaram explicar como a economina deficitária dos atos das vontades humanas pode ser revigorada com as diversas graças divinas. Nunca conseguiram mais do que desvalorizar a vontande humana e deixá-la na total dependência da graça. A moeda que deveria ser falsa, sem valor, sempre acabou por ser o que movimenta toda a economia. Ou seja, a vontade humana era fraca, incapaz de alcançar a estabilidade de uma vida virtuosa, não pecadora e não atormentada pelas tentações, foram postas graças em circulação, com isto ficou evidenciada a fraqueza da vontade, as graças se valorizaram em detrimento da vontade, de modo que o que deveria ter sido economicamente valorizado acaba por entrar em colapso. Fracasso da teologia? Não, valorização de sua própria moeda. A teologia teria fracassado se toda a possibilidade de uma economia fosse posta em descrédito, mas isso não ocorreu; seguiu-se sempre apostando na possibilidade de um fechamento econômico, seguiu-se equalizando economia restrita com pacificação e felicidade.

É importante se indicar que é esta equalização mesma entre economia restrita, pacificação e felicidade enquanto satisfação da vontade que é estruturalmente impossivel, uma vez que sempre se postulou que a vontade depende da impossibilidade do determinismo, isto é, da impossibilidade de uma economia restrita. A pacificação (enquanto uma totalização abolidora da contingência) viria sempre simultaneamente com a suspensão da vontade, com a supressão do que ela pretendia plenificar beatificadoramente. Isto já era assim nos gregos e isto foi exacerbado com o cristianismo. Ou seja, o que está e sempre esteve em jogo nunca foi como se alcançar uma totalização pacificante, mas antes a própria proposta impossivel de uma totalização. O jogo sempre foi o de se propor uma totalização inalcançável para se poder propor o que fazer para alcançá-la. Esta já era a proposta grega, a proposta do cristianismo foi exacerbar esta proposta. Assim, a graça mostrou a impossibilidade da totalização aristotélica e propôs uma nova totalização impossivel; e sempre que os teólogos tiveram de reconhecer a impossibilidade de explicar a totalização salvífica eles o fizeram sem nunca pôr em questão a própria possibilidade de uma totalização pacificante, de modo que sempre puderam seguir afirmando-a e pondo-a ainda mais na dependência da graça divina.

Significaria isto uma desconstrução? Buscou a teologia desconstruir o pensamento grego? Tudo depende de como se entenda desconstrução. Se desconstrução é haver no pensamento conceitos que funcionam de forma a impedir o fechamento deste pensamento, então desde os gregos sempre houve desconstrução. Se desconstrução é potencializar os conceitos que impedem o fechamento, então a teologia cristã é desconstrutora. Mas se desconstrução é não só impedir o fecha- 
mento, mas ainda indicar o que exige tal fechamento e como este fechamento é impossivel, então o pensamento cristão não é desconstrutor. $O$ pensamento cristão usou e usou abusivamente da impossibilidade do fechamento, mas sempre esteve recorrendo à idéia do fechamento. O pensamento cristão sempre utilizou a equalịzação entre fechamento, pacificação e beatitude. É exatamente a questão de como pensar uma teologia salvífica onde "pacificação" não se equalize com totalização uma das tarefas negligenciadas pela teologia atual.

Para concluir retornemos ao artigo de Kahn. Penso que temos ainda que questionar o que seja uma tradição, mas aceitando-se provisoriamente este conceito, tal como Kahn, como se não fosse problemático, considero que o que há de fundamentalmente diferente entre o conceito de vontade em Agostinho e o de Aristóteles é nem tanto a diferença da estrutura ontológica da vontade, mas o encontro ou 0 "engalfinhamento", isto é, a interação dissimétrica de duas tradições. Neste aspecto a voluntas de Agostinho é tão diferente da voluntas de Sêneca quanto da estrutura da vontade de Aristóteles. O que complexifica esta confluência de tradições é ela vir acompanhada de toda uma transformação da posição do homem no mundo e frente a Deus (trata-se afinal também de um outro Deus); é este novo posicionamento do homem no mundo que leva a que ele pense, ou vivencie, sua vontade como mais radicalmente dilacerada que antes, embora em última instância seja o conceito de vontade pensado e elaborado pela tradição greco-latina que esteja sendo assimilado.

Apenas estive sugerindo que este encontro de tradições não pode ser entendido meramente como uma sobreposição ou como uma acomodação mais ou menos harmoniosa, ele se dá ao mesmo tempo de um modo mais intimo e mais conflituoso. Ao menos quanto à questão da relação entre vontade e graça o que ocorreria seria uma relação de apropriação, potencialização, desarticulação, recuperação, nova potencialização etc.

Este breve comentário sugere que o encontro entre a tradição grega e a judaico-cristã se deu com o cristianismo como que colocando cunha nas brechas do pensamento grego, forçando-o para além dos seus limites para ao mesmo tempo desacreditá-lo e deixar que ele seguisse valendo como sendo afinal a única possibilidade aceitável de se pensar. Desta forma o cristianismo buscou tanto pensar seus dogmas quanto deixá-los valendo como dogma. O próprio conceito de dogma só pode ser formulado com apoio da tradição greco-latina, embora o dogma de modo algum seja uma determinação jurídica a qual, enquanto qualquer lei, pode ser seguida; antes tem-se que livremente ter fé no dogma; o dogma ordena que se acredite. Mas que se acredite em quê? Os principais dogmas são antes a afirmação de algo que não pode ser apreendido pelo intelecto, são a afirmação de um mistério. Como se acreditar no que não se pode entender? Mas o dogma exatamente ordena que se acredite no que não só não se entende, mas sequer se apreende intelectualmente. Assim o dogma de que Jesus não é nem uma imagem (docetismo) nem um homem adotado (adopcionismo), mas seria o que então? E o dogma da Trindade? E o dogma da Transubstanciação? Todos estes dogmas formulados com referência a uma linguagem filosófica, mas dizendo que os conceitos filosóficos são insuficientes para se expressar aquilo que é dogmatizado como se devendo crer. $\mathrm{E}$ 
assim também o dogma da predestinação e do livre arbitrio. Podendo-se ainda lembrar o dogma sobre a impossibilidade da certeza da fé.

Pensar melhor a relação entre estas duas tradições, a judaico-cristã e a grecoromana, é uma questão sempre ainda a ser melhor discutịda. Não se trata de duas tradições concorrendo ou se sobrepondo, mas de duas tradições interagindo conflituosa e dissimetricamente, forçando nas brechas, mas sempre buscando deixar valer aquilo que parece se estar buscando desarticular. 